\title{
Stainless steel finned tube heat exchanger design for waste heat recovery
}

\author{
K P M Wipplinger \\ Department of Mechanical Engineering, University of Stellenbosch \\ T M Harms \\ Department of Mechanical Engineering, University of Stellenbosch
}

A B Taylor

Stellenbosch Automotive Engineering (Pty) Ltd

\begin{abstract}
Around the world the implementation of heat recovery systems play an increasingly important role in the engineering industry. Recovered energy is utilised in production plants (especially in the food industry) and saves companies millions in expenses per year. Waste heat recovery associated with hydrocarbon combustion in the transport industry is identified as a significantly under-utilised energy resource. The aim of this project was to investigate the recovery of waste heat in a small scale system for the purpose of electrical conversion in order to serve as a secondary energy source. A theoretical analysis concerning the design and construction of the system, utilising researched theory and a control-volume-based simulation program of the recovery system, is presented. It was found that heat exchangers for the required duty are not readily available in South Africa. A high pressure, cross flow, stainless steel finned tube heat exchanger with a water side pressure rating of $2 \mathrm{MPa}$ was therefore designed and constructed. By using the exhaust gases of a continuous combustion unit as an energy source and water as the working fluid, efficiencies of up to $74 \%$ in direct steam generation testing were obtained.
\end{abstract}

Keywords: stainless steel heat exchanger, high pressure, high temperature, radial finned tubes

\footnotetext{
Nomenclature

C friction factor

c specific heat, J/kg.K

d diameter, $m$

$\mathrm{dp}$ differential change in pressure, $\mathrm{N} / \mathrm{m}^{2}$

$\mathrm{dz}$ differential change in distance, $\mathrm{m}$
}

F enhancement factor (eq. 19, 21)

$\mathrm{G}$ total (liquid+gas) mass flux, $\mathrm{kg} / \mathrm{m}^{2} \mathrm{~s}$

Gr Grashof number

g gravitational constant, $\mathrm{m} / \mathrm{s}^{2}$

$\mathrm{h}$ heat transfer coefficient (eq. 17-19), $\mathrm{W} / \mathrm{m}^{2} \cdot \mathrm{K}$

$\mathrm{h}_{\mathrm{fg}} \quad$ latent enthalpy of vaporisation, $\mathrm{J} / \mathrm{kg}$

hyd hydraulic

$\mathrm{K}$ thermal conductivity, $\mathrm{W} / \mathrm{m} . \mathrm{K}$

$\mathrm{L}$ length, $\mathrm{m}$

$\mathrm{P}$ pressure, $\mathrm{Pa}$

Ra Rayleigh number

$\mathrm{Re}$ Reynolds number

$\mathrm{S}$ slip ratio (eq. 9, 10); suppression factor (eq. 18, 20)

$\mathrm{T}$ temperature, $\mathrm{K}$ or ${ }^{\circ} \mathrm{C}$

$\mathrm{V}$ velocity, $\mathrm{m} / \mathrm{s}$

We Weber number

X Lockhart-Martinelli parameter

$\mathrm{x}$ two-phase quality

$\Delta \quad$ finite increment

$\alpha$ void fraction

$\beta \quad$ inverted average temperature, $\mathrm{K}$

$v \quad$ kinematic viscosity, $\mathrm{kg} / \mathrm{m} . \mathrm{s}$

$\rho \quad$ density, $\mathrm{kg} / \mathrm{m}^{3}$

$\mu \quad$ dynamic viscosity, N.s $/ \mathrm{m}^{2}$

$\sigma \quad$ surface tension, $\mathrm{N} / \mathrm{m}$

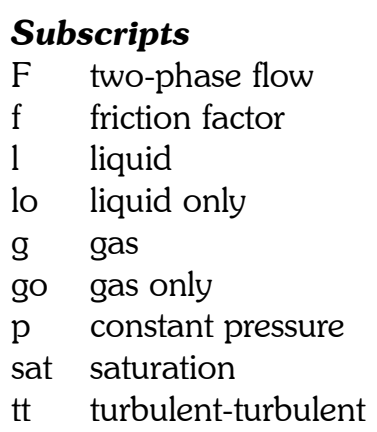




\section{Introduction}

The mid $20^{\text {th }}$ century has proven to be a time during which the world has had a rude awakening from its relaxed attitude towards the usage of our depleting natural resources. Proof of this is the waste heat recovery systems that have been in use in industries all over the world for the last 50 years. An example of this is the integration of various factory sections where the waste heat from one section is used in another. This is common practise in the food industry and not only saves money, but streamlines production and results in better efficiencies. Nonetheless, a large amount of energy is still being lost in the form of heat generated by everyday industrial and domestic equipment (Koorts 1998).

The definition of waste heat includes the following: unburned but combustible fuel; sensible and latent enthalpy discharge from exhaust gas mixtures; and sensible heat discharge in liquid waste (Al Rabghi et al 1993).

A quarter of the energy consumption in the western world is centred in the transportation sector. Automobiles and trucks account for approximately $80 \%$ of all transportation energy expenditures. These thermal engines operate with a thermal efficiency between 30 and 40\% (Koehler et al 1997).

The typical energy balance for a turbocharged diesel engine, as tested by Stellenbosch Automotive Engineering (Wipplinger 2000), is as follows: oil cooling $(2 \%)$, air cooling $(5 \%)$, water cooling $(25 \%)$, exhaust gasses $(33 \%)$ and mechanical power $(35 \%)$. It is clear that approximately one third of the total energy released by the combustion process is lost along with the exhaust gas, while one third is transferred to the cooling fluids and the rest is converted to actual mechanical power. The cooling fluids are necessary losses which prevent catastrophic failure of the engine due to overheating. But the energy lost along with the exhaust gas, can be ascribed to the inefficient utilisation of the available energy, which makes research into the recovery of waste energy and subsequent efficiency and fuel utilization improvement, a viable option.

While it is well known that sensible hydro-carbon combustion waste heat recovery is a common practice in large units found in marine applications, the present study forms part of ongoing investigations desiring to examine ways for exhaust gas waste heat recovery on smaller units, e.g. trucks and locomotive engines. The final system design would ideally convert the recovered energy into electricity by implementing a turbine and generator combination.

In a detailed study done by Wipplinger (2004), the following premises were accepted: The sensible heat must be recovered by means of a heat exchanger, which will impose a low back pressure on the exhaust system. Latent enthalpy recovery is not envisaged at present as the condensation of any vapours present in the exhaust gas mixture is considered unfavourable to the exhaust system. Without committing to a downstream Rankine steam cycle and its variations (e.g. a Stirling engine might serve as an alternative), high pressure capability on the water side would be required. For various reasons discussed by Wipplinger (2004), a finned tube cross-flow configuration was considered the most suitable. In order to correctly specify such a unit, knowledge of the behaviour of two-phase flow and its subsequent heat transfer coefficients, are required.

\section{Two-phase correlations}

During the heat exchanger design process, described by Wipplinger (2004), a computer program was written in Microsoft ${ }^{\circledR}$ Visual Basic 6 which simulated the conditions, and subsequent fluid/gas properties, inside the heat exchanger. Well known correlations were used to compensate for the various flow regimes, of which the following are the most important:

\section{Friedel Correlation for Frictional Two-phase Pressure Gradient}

The Friedel Correlation (Friedel 1979) is probably the most generally available correlation for the frictional two-phase pressure gradient. It is written in terms of a two-phase multiplier

$$
\phi_{l o}^{2}=\frac{\left(-\frac{d p}{d z}\right)_{F}}{\left(-\frac{d p}{d z}\right)_{l o}}
$$

approximated by

$$
\phi_{l o}^{2}=E+\frac{3.24 F H}{F r^{0.045} W e^{0.035}}
$$

with

$$
\begin{aligned}
& E=(1-x)^{2}+x^{2} \frac{\rho_{l} C_{f g o}}{\rho_{g} C_{f l o}} \\
& F=x^{0.78}(1-x)^{0.224} \\
& H=\left(\frac{\rho_{l}}{\rho_{g}}\right)^{0.91}\left(\frac{\mu_{g}}{\mu_{l}}\right)^{0.19}\left(1-\frac{\mu_{g}}{\mu_{l}}\right)^{0.7} \\
& F r=\frac{G^{2}}{g d \rho_{h}^{2}} \\
& W e=\frac{G^{2} d}{\sigma \rho_{h}} \\
& \rho_{h}=\left(\frac{x}{\rho_{g}}+\frac{1-x}{\rho_{l}}\right)^{-1}
\end{aligned}
$$




\section{CISE Correlation for Void Fraction}

The correlation of Premoli et al. (1970), usually known as the CISE correlation, is a correlation determining the void fraction in terms of a slip ratio, $S$. The void fraction $(\alpha)$ is given by

$$
\alpha=\frac{1}{1+\left(S \frac{1-x}{x} \frac{\rho_{g}}{\rho_{l}}\right)}
$$

and the slip ratio by

$$
S=1+E_{1}\left(\frac{y}{1+y E_{2}}-y E_{2}\right)^{0.5}
$$

then

$$
y=\frac{\beta}{1-\beta}
$$

$$
\beta=\frac{\rho_{l} x}{\rho_{l} x+\rho_{g}(1-x)}
$$

$E_{1}=1.578 \mathrm{Re}^{-0.19}\left(\frac{\rho_{l}}{\rho_{g}}\right)^{0.22}$

$E_{2}=0.0273 W e \operatorname{Re}^{-0.51}\left(\frac{\rho_{l}}{\rho_{g}}\right)^{-0.08}$

$\operatorname{Re}=\frac{G d}{\mu_{l}}$

$$
W e=\frac{G^{2} d}{\sigma \rho_{l}}
$$

$h_{\text {mic }}=0.00122 \frac{k_{l}^{0.79} c_{p l}^{0.45} \rho_{l}^{0.49}}{\sigma^{0.5} \mu_{l}^{0.29} h_{f g}^{0.24} \rho_{g}^{0.24}} \Delta T_{s a t}^{0.24} \Delta P_{\text {sat }}^{0.75} \cdot S$

$\Delta \mathrm{T}_{\text {sat }}$ is the wall superheat in Kelvin and $\Delta \mathrm{P}_{\text {sat }}$ is the difference between the saturation pressures calculated from the wall temperature and the fluid temperature in Pascal.

$$
h_{\text {mac }}=0.023\left[\frac{G(1-x) D}{\mu_{l}}\right]^{0.8}\left[\frac{\mu c_{p}}{k}\right]_{l}^{0.4} \frac{k_{l}}{D} F
$$

then

$$
S=\frac{1}{1+2.53 \times 10^{-6} F^{1.25} \frac{G(1-x) D}{\mu_{l}}}
$$

Parameter S (suppression factor) corrects the fully developed nucleate boiling prediction of $h_{\text {mic }}$ to account for the fact that, as the macroscopic convective effect increases in strength, nucleation is more strongly suppressed. Parameter F (enhancement factor) is calculated as

$F= \begin{cases}1.0 & \cdots \frac{1}{X_{t t}} \leq 0.1 \\ \left.2.35\left(\frac{1}{X_{t t}}+0.213\right)\right)^{0.736} & \cdots \frac{1}{X_{t t}}>0.1\end{cases}$

and the Lockhart-Martinelli parameter is calculated as

$X_{t t}=\left(\frac{1-x}{x}\right)^{0.9}\left(\frac{\rho_{g}}{\rho_{l}}\right)^{0.5}\left(\frac{\mu_{l}}{\mu_{g}}\right)^{0.1}$

All three of the above mentioned correlations and basic thermodynamic principles, were integrated in the simulation program.

The input data needed to successfully simulate the heat exchanger included the material properties and dimensions of the heat exchanger, as well as the inlet temperature and pressure properties of both the working fluid and the exhaust gas.

\section{Heat exchanger material}

As stated previously, the design most suited for the application, due to its compact size, would be a cross flow heat exchanger with a continuous finned tube criss-crossing the path of the hot gas. This would entail using a combination of U-tubes and straight finned tubes with a single heat exchanger inlet and outlet.

The project scope demanded that testing be done at high pressures and temperatures to determine their respective influence on the energy recov-

with the total heat transfer coefficient equal to the sum of a microscopic (nucleate boiling) contribution, $\mathrm{h}_{\text {mic }}$, and a macroscopic (bulk convective) contribution, $h_{\text {mac }}$. 
ery process. Due to this extreme combination, a fin and tube material had to be chosen that would withstand the conditions without failing and result in the best possible heat transfer. The materials' resistance to corrosion was also important, because of the corrosive nature of exhaust gasses.

Materials like aluminium have a very good conductivity, but tend to soften at elevated temperatures. Copper has a very high melting point, but starts to flake and disintegrate long before it reaches its melting point temperature. It would also start 'ballooning' at the U-bends, because of the high pressures inside the heat exchanger tubes. Due to the corrosive environment it would be subjected to, carbon and mild steel were also ruled out because of the inevitable decrease in heat exchanger effectiveness, should corrosion occur.

After some consideration the material chosen for both the fins and tubes, was stainless steel. Despite stainless steel's low thermal conductivity, it has a very good resistance to corrosion and can be used at high temperatures. By utilising the same material for the fins and tubes, the resulting solid finned tube would have no contact resistance and would improve the heat transfer.

For stainless steel, an optimal fin height of $5 \mathrm{~mm}$ was determined necessary. Stainless steel tends to work harder, so to extrude the fins, or roll them onto the tube would not be feasible. Therefore, it was decided to use a hollow bar and machine cut the fins out with the help of a numerically controlled milling machine (NC-machine).

While this type of heat exchanger design meets the experimental needs and the engineering department's workshop manufacturing capability at Stellenbosch University, it has not been optimised for manufacturing on any scale. Although modern computerized production workshops are highly cost effective in handling variations of small batch designs, alternatively more conventional heat exchanger construction methods are not ruled out. However, deliberations of this kind are considered premature at this stage of the research.

The optimal heat exchanger design was determined using the simulation program by entering various heat exchanger dimensions (i.e. the finned tube dimensions and the number of tube-rows within the heat exchanger) along with the material properties of stainless steel and the inlet conditions of the working fluid and exhaust gas.

The optimising strategy incorporated state of the art heat transfer theory with which, after several iterations, the program computed the resulting heat exchanger outlet conditions for a given set of input parameters, as discussed above. These results were then compared and the ideal design identified.

Heat exchanger construction and testing The heat exchanger simulation resulted in the fol- lowing optimised dimensions: fin height, $5 \mathrm{~mm}$; fin thickness, $0.5 \mathrm{~mm}$; fin pitch, $2 \mathrm{~mm}$. Each finned tube was $306 \mathrm{~mm}$ in length and resulted in the completed heat exchanger having outer dimensions of $420 \times 403 \times 200 \mathrm{~mm}^{3}$. A machined finned tube is shown in Figure 1.

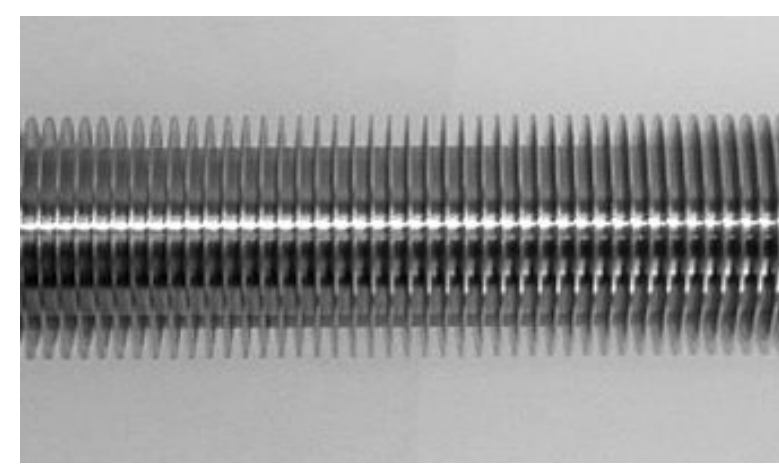

Figure 1: NC-machined finned tube

The U-tubes were interference fitted inside the finned tubes and then TIG-welded together. As a precaution, the fully assembled heat exchanger was pressure tested up to $3000 \mathrm{kPa}$. Under testing conditions, the pressure would not exceed $2000 \mathrm{kPa}$ as set by the project goals.

Figures 2 and 3 shows the completed heat exchanger assembly, as well as the points at which pressure and temperature measurements were taken on the heat exchanger and exhaust gas ducting.

To determine the characteristics of the heat exchanger under various operating conditions, experimental testing was done using a continuous combustion unit (which supplied the exhaust gas) and water (which served as the heat recovery fluid). To enable testing at various pressures, a speed controlled water pump was connected to the inlet of the heat exchanger and a pressure valve was connected to the outlet of the heat exchanger. Temperature control was obtained by using various air-fuel mixtures inside the continuous combustion unit.

\section{Actual and simulated heat exchanger results}

The evaluation of the experimental and simulated test results consisted of the comparison of the inlet and outlet properties in both cases.

Figure 4 shows the results of an experimental test compared to the results of a simulated test at the same inlet conditions. The figure illustrates the temperature distribution as measured by the thermocouples that were TIG-welded to the U-tubes as shown in Figure 2. Between thermocouples 1 and 4, Figure 4 shows a steeper actual temperature gradient than was predicted by the simulation. These thermocouples are in the first two rows of the heat exchanger as shown in Figure 5. From there onwards, the temperature gradient rises through a 


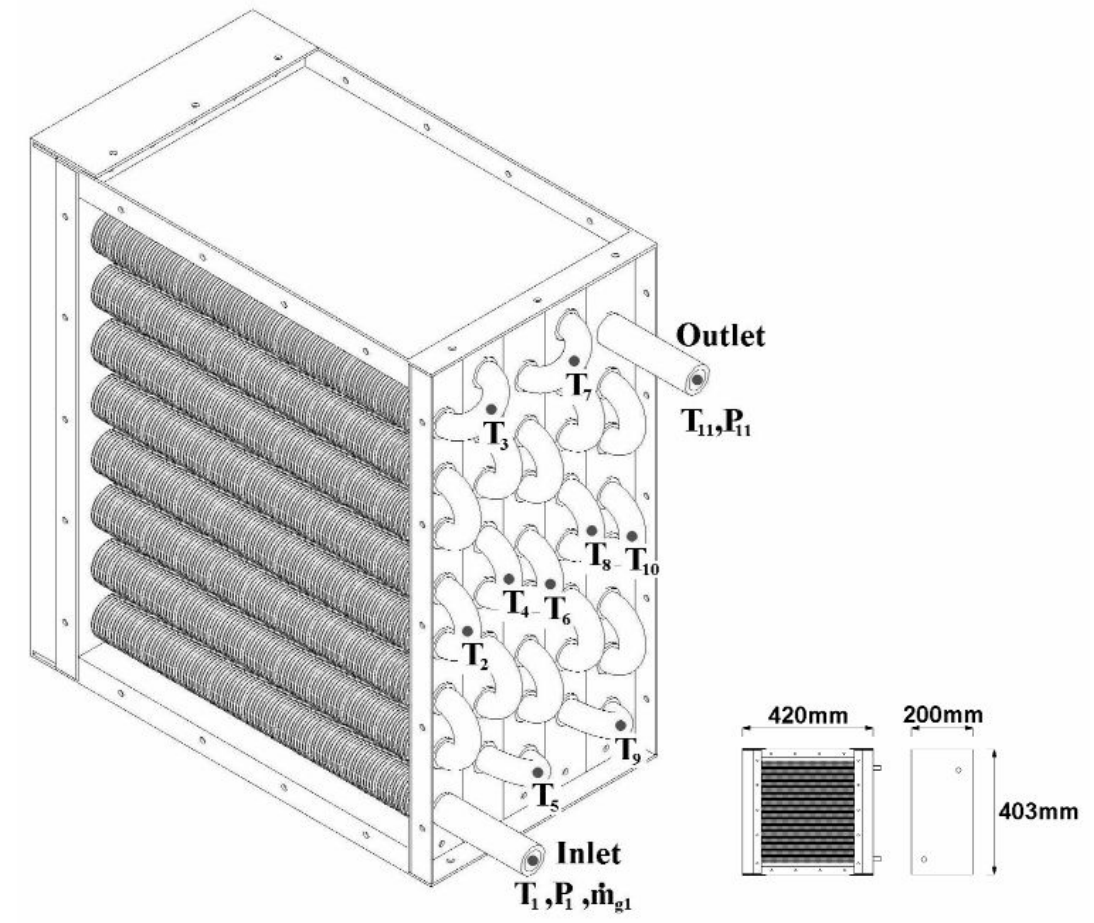

Figure 2: Measurements taken on the heat exchanger

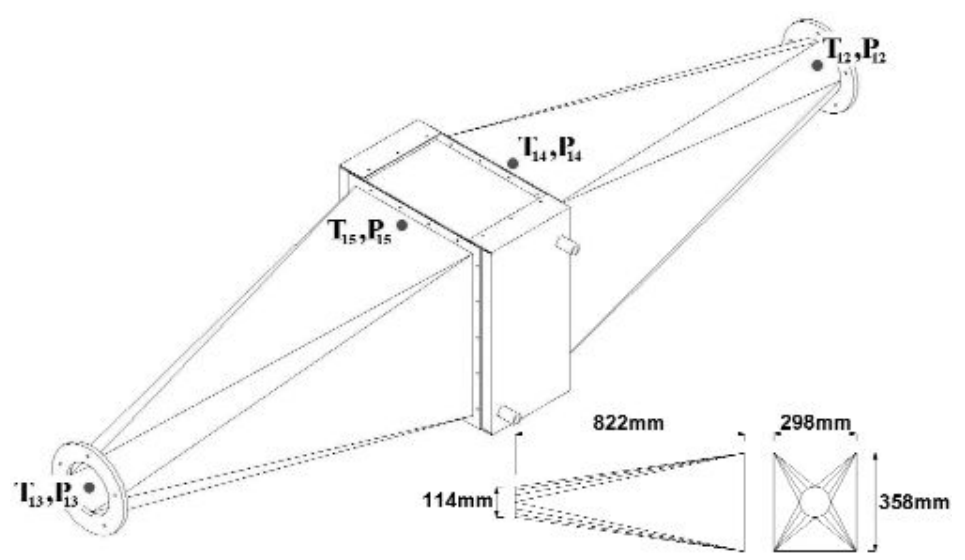

Figure 3: Measurements taken on the exhaust inlet ducting

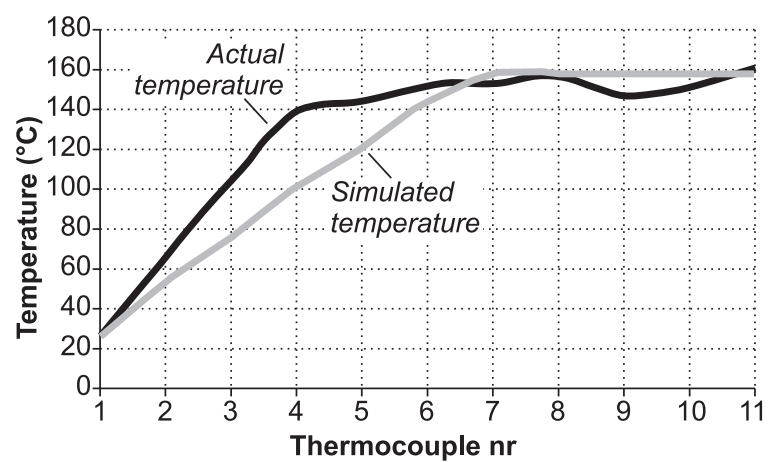

Figure 4: Actual versus simulated temperatures inside the heat exchanger

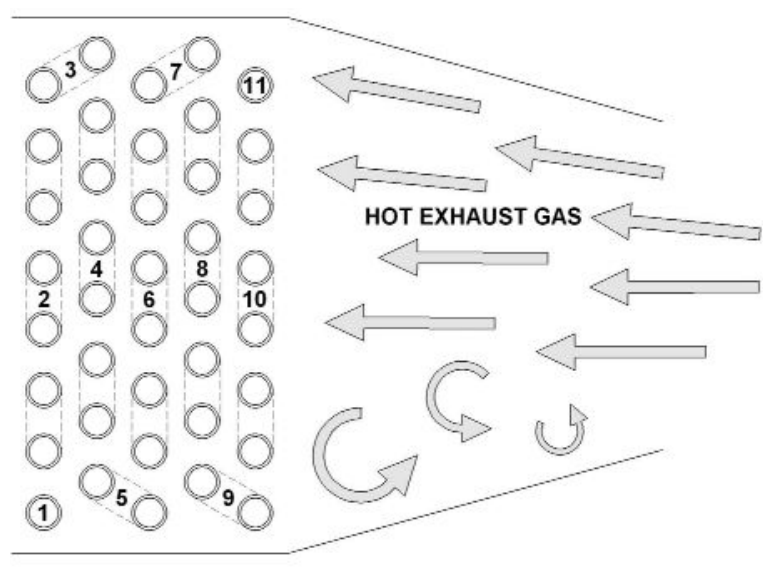

Figure 5: Exhaust gas distribution inside the ducting 
series of steps and becomes negative between thermocouples 8 and 9 .

This was hypothesised that this anomalous behaviour could be explained by the distribution of hot exhaust gas flowing through the heat exchanger. Figure 5 shows the expected exhaust flow. As the exhaust gas enters the ducting, it rises to the top half of the ducting, creating turbulent vortices in the bottom half.

These turbulent vortices will result in a better heat transfer through the bottom and sides of the ducting, cooling the exhaust down and exposing the lower parts of rows 3, 4 and 5 to a lower temperature; the end result being the actual cooling of the liquid-vapour mixture inside the finned tubes. This hypothesis was tested using convection theory.

$$
G r=\frac{\beta \Delta T g L^{3}}{v^{2}}
$$

where

$$
\begin{aligned}
& \Delta \mathrm{T}=\mathrm{T}_{\text {gas }}-\mathrm{T}_{\mathrm{s}} \\
& \beta=\frac{1}{T_{a v}}=\frac{2}{T_{\text {gas }}-T_{\text {surf }}}
\end{aligned}
$$

and $\mathrm{T}_{\mathrm{av}}$ is in Kelvin.

The Reynolds number is determined by

$$
\mathrm{Re}=\frac{\mathrm{V} \cdot \mathrm{D}_{\text {hyd }}}{\mathrm{v}}
$$

and the Rayleigh number by

$$
\mathrm{Ra}=\mathrm{Gr} \cdot \mathrm{Re}
$$

By using a range of values for $\mathrm{T}_{\text {surf }}$ between 25 and $340^{\circ} \mathrm{C}$ along with Mills (1995), the results show that mixed convection conditions occur inside the ducting. This would result in a secondary motion where the exhaust gas would flow upwards along the wall and downwards in the central region forming a vortex which would increase the heat transfer and result in a lower exhaust temperature. A way of eliminating this would be to ensure the equal distribution of the hot exhaust gas through the ducting with the help of guide vanes. In addition, Van Zyl et al (2006) also conducted a CFD simulation of the gas flow inside the ducting. Some generic results from that research are shown in Figure 6 and typically indicate flow separation and re-circulation of the gas occurring.

Another interesting phenomenon shown by Figure 4 is the fact that the inlet gradient between thermocouples 1 and 4 is much steeper than predicted by the simulation program. The explanation for this phenomenon has a connection to the exhaust extraction fan which was situated at the outlet of the exhaust ducting. In experimental testing, a change in the heat transfer coefficient was noted when the fan was switched on, while no notable change was measured in the air mass flow rate at the continuous combustion unit.

The flow meter restricts air flow when set to a certain volumetric flow rate, while the exhaust fan increases the suction at the outlet of the ducting. The result is a low pressure zone which forms between the heat exchanger and the exhaust fan prompting the acceleration of the gas and giving a higher heat transfer coefficient within the heat exchanger. This was confirmed by the experimental measurements as the simulated pressure drops (approximately $1 \mathrm{~Pa}$ ) was much lower than the actual pressure drop (approximately 8-10 $\mathrm{Pa}$ ) across the heat exchanger.

Figure 7 (the use of different inlet conditions) shows similar temperature behaviour, as described in Figure 4. From Figure 7, it is evident that test runs 5 and 9 as well as test runs 8 and 10 follow the same temperature path for the last half of the heat exchanger, despite the fact that they have different starting gradients.

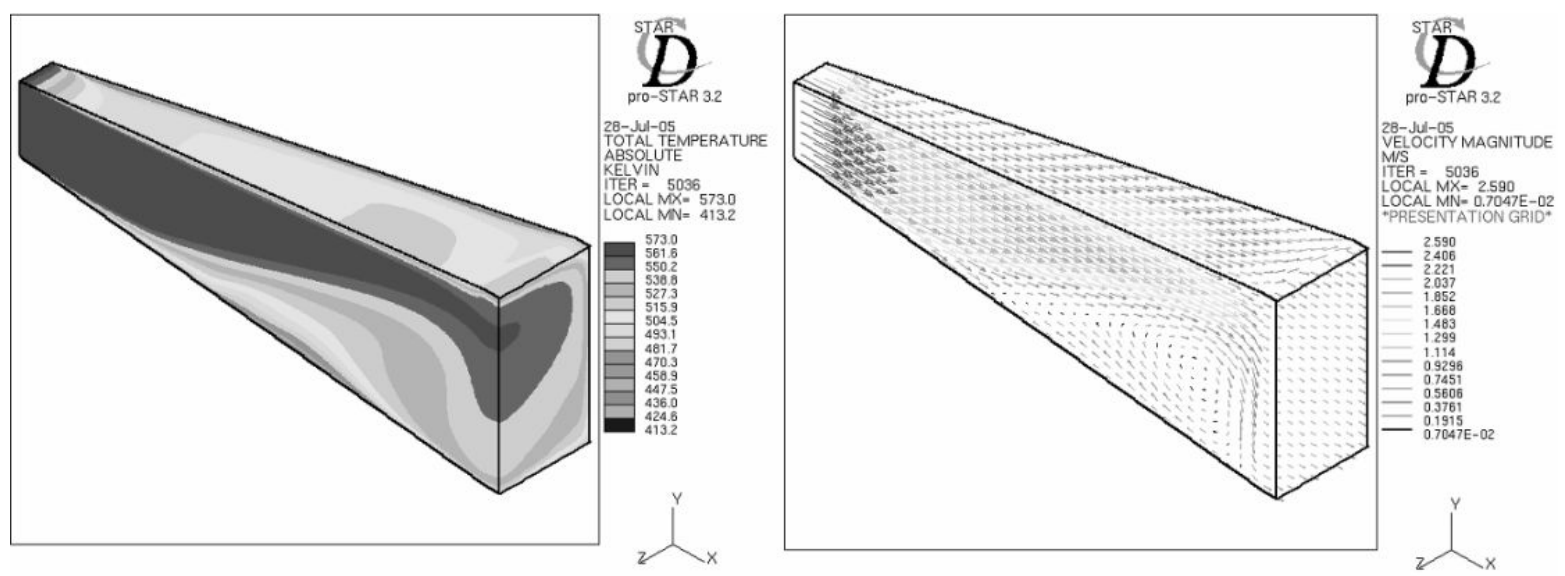

Figure 6: (left) A sectional temperature distribution through a diffuser (right) A sectional velocity field through a diffuser 


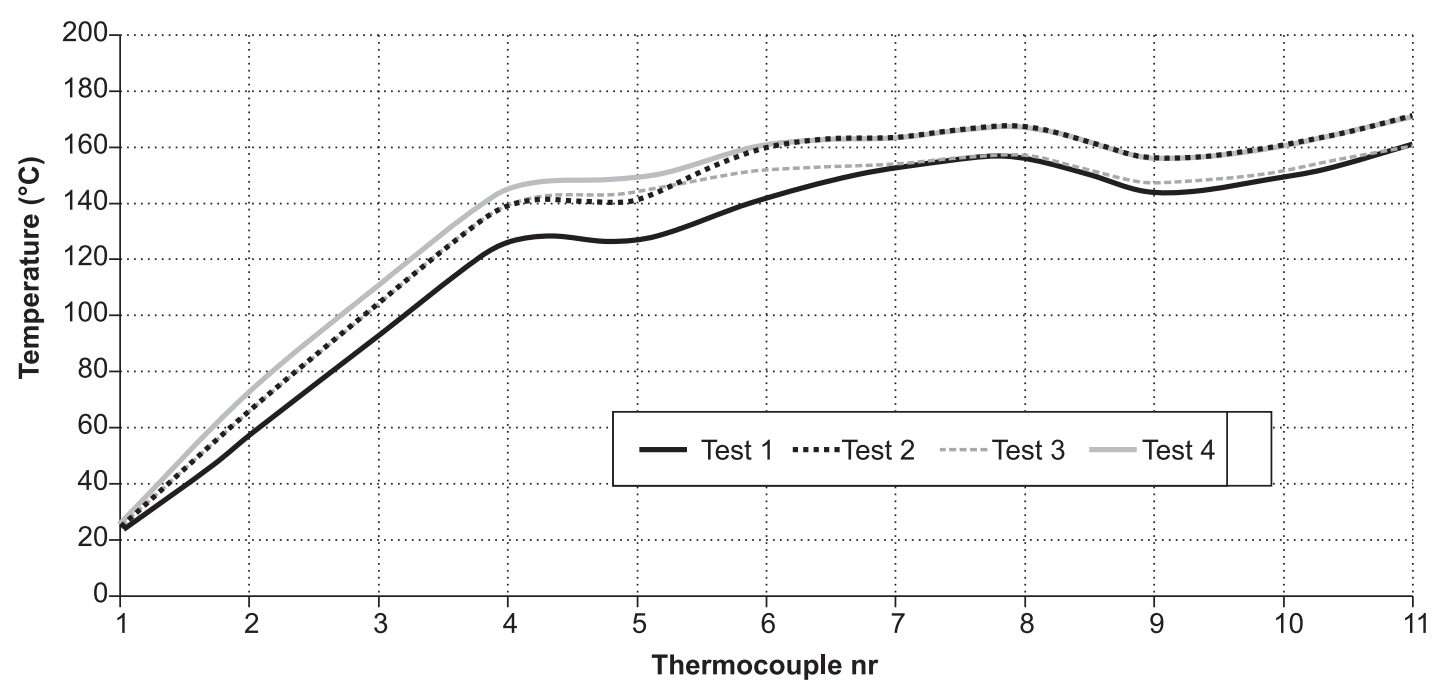

Figure 7: Test point comparisons

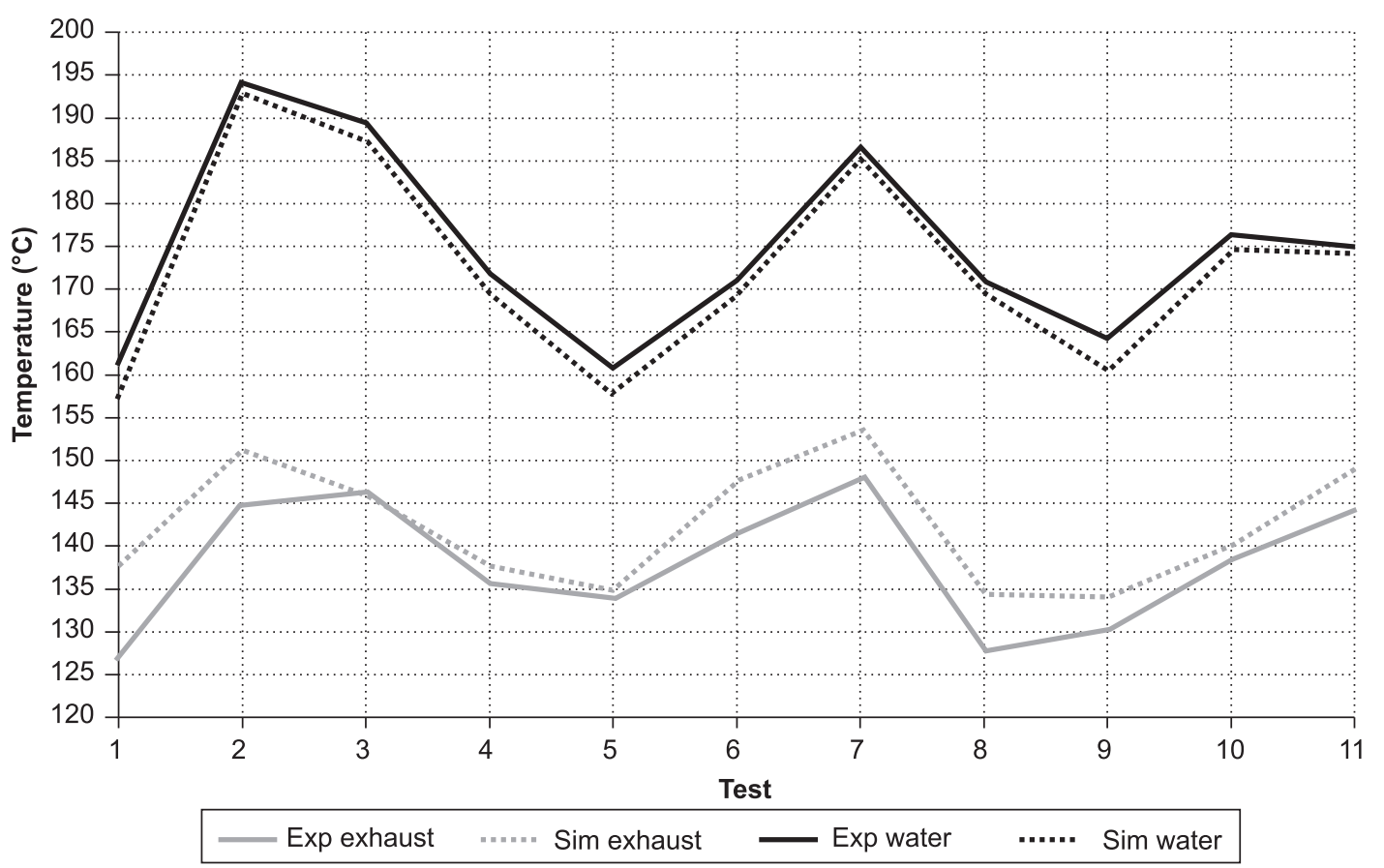

Figure 8: Actual and simulated outlet temperatures

The explanation for this occurrence is the fact that test runs 1 and 3 both had an inlet pressure of $600 \mathrm{kPa}$, while test runs 2 and 4 were at $800 \mathrm{kPa}$. The similar pressures meant that they would evaporate at the same saturation temperatures. The fact that all of the tests had different exhaust gas temperatures and/or flow rates, explains the different temperature gradients at the beginning of each curve.

To verify the baseline conditions with which the simulation results could be compared, all electronic measuring equipment used in the experiment, were calibrated beforehand. Figure 8 shows the results of 11 comparative test runs that were done. On aver- age, the difference between inlet and outlet temperatures for the actual and simulated exhaust gas, varied by $-1.99 \%$. In other words, the amount of simulated energy transferred was less than the actual energy transferred. The same comparison for the working fluid, showed a variation of $-1.47 \%$. In other words, the amount of simulated energy transferred was again less than the actual energy transferred. The reason why these two values are different is because the simulation program does not take any losses into account.

This is evident when comparing the amount of energy transferred. On average, the simulated and actual exhaust gas energy transferred, differed by 


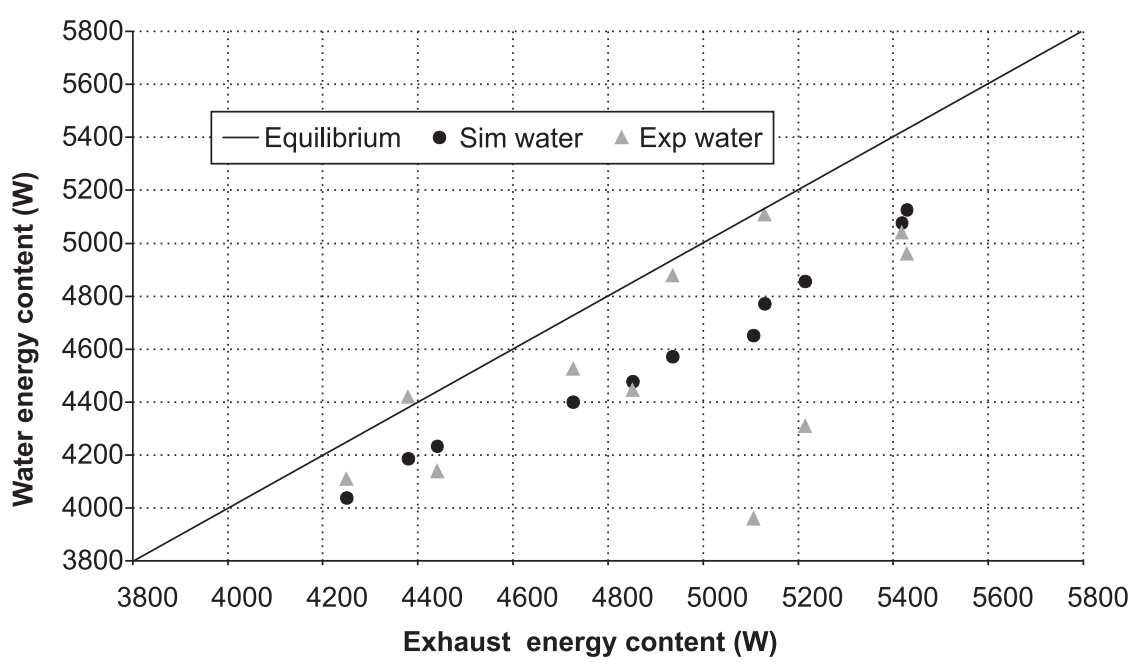

Figure 9: Heat exchanger experimental and simulated energy balance

$6.41 \%$, while the simulated and actual energy transfer of the working fluid differed by $7.16 \%$.

Figure 9 shows the energy balance for both the experimental and simulated cases. The experimental values are much more scattered than the simulated values, in part due to the fact that the simulation theory did not take the pulsating/plug flow into account. Thus, the simulated values form a relatively straight line beneath the equilibrium line, where the distance between the simulated and equilibrium line can be ascribed to losses.

From the comparative tests shown above, it was concluded that the simulation program, despite some minor inaccuracies by not taking losses into account, is a true representation of the characteristic behaviour of the heat exchanger. The highest efficiency reached by the heat exchanger in experimental testing was $74 \%$. Although, by using certain inlet conditions, the simulation program predicts that the heat exchanger efficiencies could be as high as $87 \%$.

\section{Further simulation testing}

In an attempt to further characterise the heat exchanger, various simulated test runs were done using different inlet conditions.

Data corresponding to the steam quality crossover from $\mathrm{x}<1$ to $\mathrm{x}=1$, clearly showed the various characteristics of the fluid temperature, inlet- and outlet pressures, thermal heat transfer coefficient and the enthalpy. The data was generated by keeping the inlet temperatures and mass flow rates constant, while varying the inlet pressures.

A summary of the results is illustrated in Figure 10 which shows the relationship between the water temperatures and the inlet pressures of the heat exchanger. From the 3D graph it is evident that between inlet pressures of 400 and $1200 \mathrm{kPa}$, the outlet temperatures drop, while a temperature rise is noted above $1300 \mathrm{kPa}$. $\mathrm{T}_{\text {sat }}$ also rises as the pressure is increased and can be seen as a steadily rising plateau.

The pressure increase prompts the vapour saturation point on each curve to slowly disappear until the steam quality drops below $100 \%$ and becomes a liquid/vapour mixture.

In Figure 11 the heat transfer coefficient curve peaks at a lower value when the pressure is increased. This would indicate that the amount of energy transferred decreases as the pressure increases.

The discontinuities shown on each curve, indicates that the water is flowing through a row closer to the inlet exhaust gas and is thus exposed to a different exhaust temperature, changing the heat transfer coefficient. In the first four test runs, the first discontinuity is caused by theory inconsistencies. The effect this has on the results is insignificant and does not justify implementing a different theory.

By using the input values shown in Table 1, a characteristic heat transfer coefficient curve was generated.

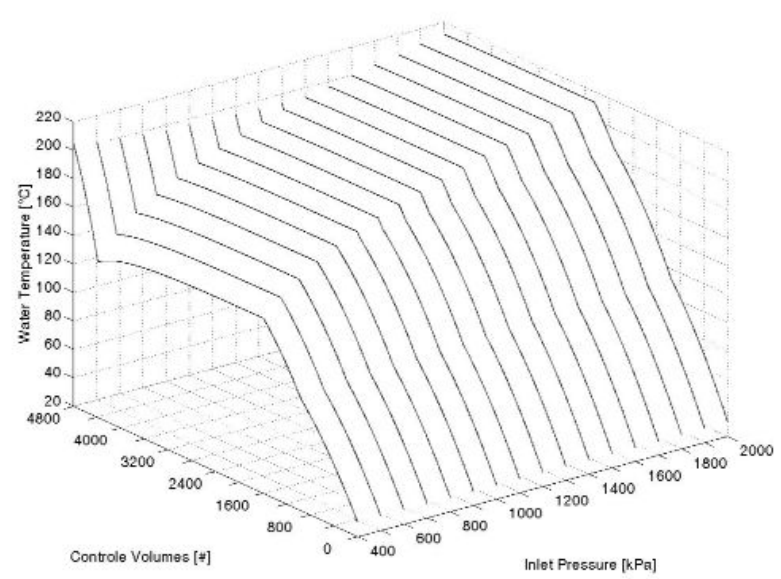

Figure 10: Water temperature distribution 


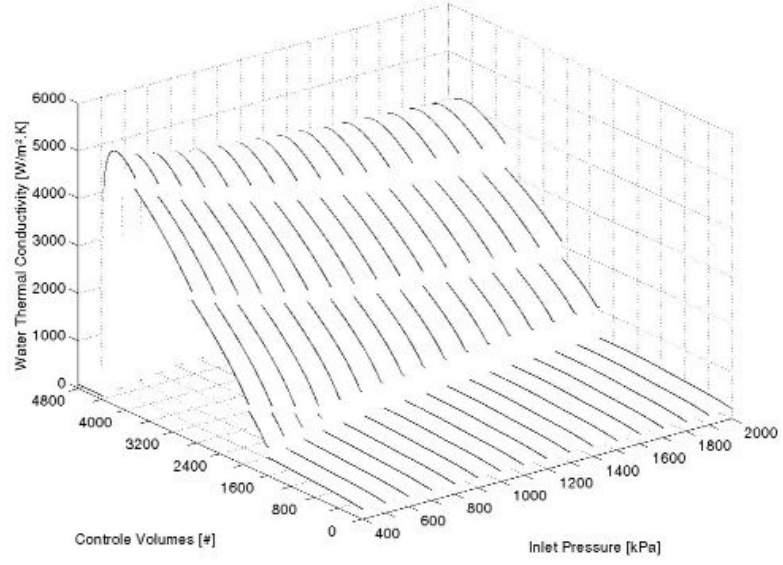

Figure 11: Water thermal heat transfer coefficient

Table 1: Gas/fluid input values

\begin{tabular}{lcc}
\hline Inlet conditions & Gas & Water \\
\hline Temperature $\left({ }^{\circ} \mathrm{C}\right)$ & 400 & 25 \\
\hline Pressure $(\mathrm{kPa})$ & 101.4 & 1000 \\
\hline Mass flow rate $(\mathrm{kg} / \mathrm{s})$ & 0.0233 & 0.0015 \\
\hline
\end{tabular}

The results, plotted in Figure 12, correspond to data provided by Odeh et al (1998), where the modelling of a parabolic trough with direct steam generation was done. The first horizontal line represents the preheated region (liquid water), the vertical line indicates the two-phase region (watervapour mixture) and the last horizontal line indicates the superheated region (superheated steam). The correspondence between the simulated heat exchanger data and the data of a parabolic trough is explained by the fact that a heat exchanger is nothing more than a parabolic trough with the collector replaced by fins and the absorption-tube neatly folded into a zigzagged configuration.

\section{Conclusion}

This project is a good example of technology working to preserve our resources, where an effort has been made to try and minimise energy losses, which will result in less fuel usage. Although the heat exchanger design is only a small step in the development of a complete small scale recovery plant, which can be used in the truck or locomotive industry, it none the less forms a valuable foundation on which the whole system can be built.

The comprehensive research and testing done in this project, helped to define the characteristics of the heat exchanger and by including a simulation program, it will now be possible to simulate the whole recovery system based on these characteristics given certain inlet properties.

The next step in the ongoing research project will be to incorporate a means of energy conversion, be it a sterling engine or a turbine and generator combination.

\section{References}

Al Rabghi O.M., Bierutty M., Akyurt M., Najjar Y. and Alp T. (1993), Recovery and utilization of waste heat, A review paper, Heat Recovery Systems and CHP, Vol. 13, pp. 463-670.

Chen J.C. (1963), A correlation for boiling heat transfer to saturated fluids in convective flow, ASME paper 63-HT-34. Presented at the 6th National Heat Transfer Conference, Boston.

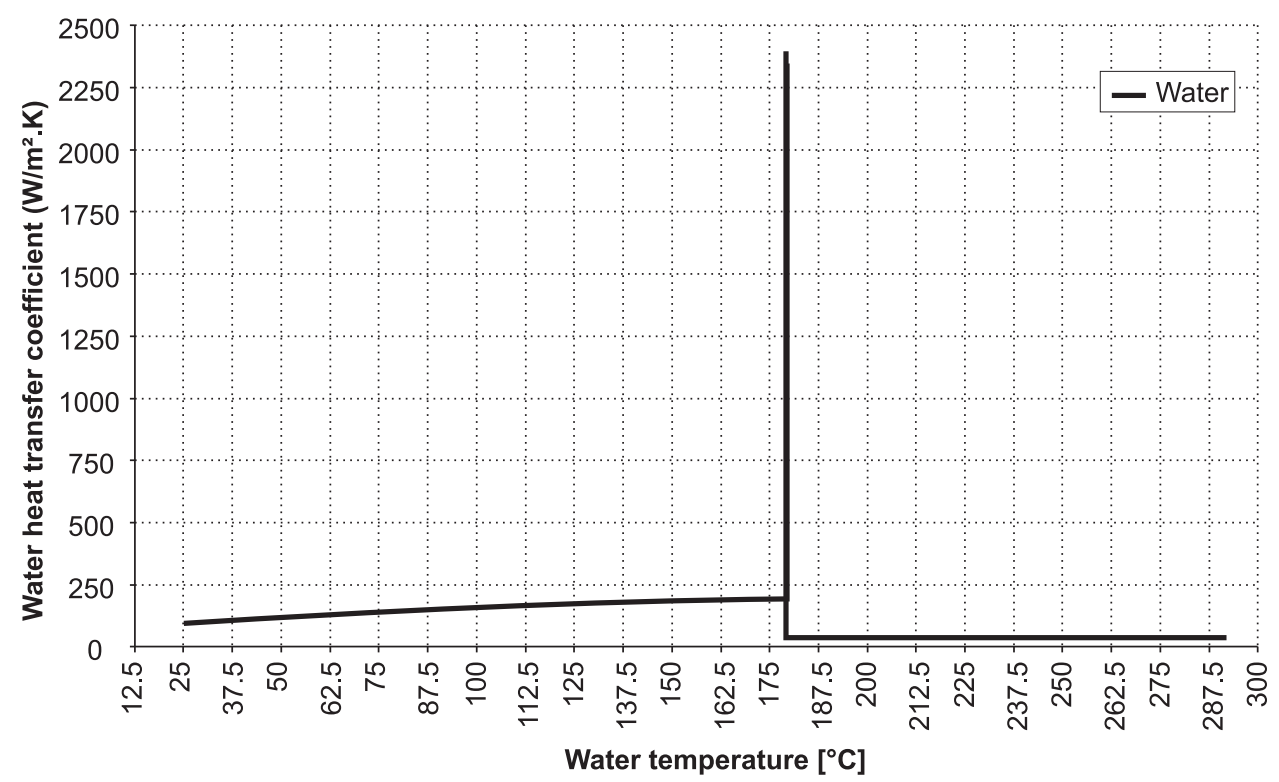

Figure 12: Water heat transfer coefficient vs. temperature 
Forster H.K. and Zuber N. (1955), Dynamics of vapour bubbles and boiling heat transfer, AIChEJ., Vol. 1, pp. 531-535.

Friedel L. (1979), Improved friction drop correlations for horizontal and vertical two-phase flow, European Two-phase Flow Group Meeting, Ispra, Italy.

Koehler J., Tgethoff W.J., Westpalen D. and Sonnekalb M. (1997), Absorption refrigeration systems for mobile applications utilising exhaust gasses, Heat and Mass Transfer, Vol. 32, pp. 333-340.

Koorts T. (1998), Waste energy recovery system, Final Year B Eng Project, University of Stellenbosch, August.

Mills A.F. (1995), Heat and Mass Transfer, University of California, Los Angeles, Appendix A and Chapter 4 Figure 4.42 , p. 312.

Odeh S.D., Morrison G.L. and Behnia M. (1998), Modelling of parabolic trough direct steam generation solar collectors, Solar Thermal Energy Laboratory, University of New South Wales, Solar Energy, Vol. 62, Nr. 6, pp. 395-406.

Premoli A., Frencesco D. and Prina A. (1970), An empirical correlation for evaluating two-phase mixture density under adiabatic conditions, European Two-phase Flow Group Meeting, Milan.

Van Zyl J.M., De Rouw B., Harms T.M. and Taylor, A.B. (2006), CFD investigation of an experimentally detected heat transfer phenomenon, Extended abstract accepted: SACAM06, SAAM, Cape Town.

Whalley P.B. (1987), Boiling, Condensation, and GasLiquid Flow, Department of Engineering Science, University of Oxford, Oxford, Chapters 1-6, 16, 17, 20.

Wipplinger K.P.M. (2000), Internal combustion engine practical, Thermodynamics $\mathrm{B}$, Presented by the Centre for Automotive Engineering, University of Stellenbosch, December.

Wipplinger K.P.M. (2004), High pressure stainless steel fintube heat exchanger design for waste heat recovery, M Sc (Eng) thesis, University of Stellenbosch, April. 